\title{
Sales Company Bidding Method Based on Spread Back Strategy
}

\author{
Bin Zhao, a, Kaoshe Zhang ${ }^{1, b}$, Gang Zhang ${ }^{1, c}$, Ye Yan ${ }^{1, d}$, Zihan Ma1, e, \\ Yongqing Wang ${ }^{2, \mathrm{f}}$, Fuchao $\mathrm{Liu}^{3, \mathrm{~g}}$ \\ ${ }^{1} X i ' a n$ University of Technology, Xi'an, China; \\ 2Shaan Xi Electric Science Research Institute, Xi'an, China; \\ ${ }^{3}$ Gan Su Electric Science Research Institute, Lanzhou, China. \\ a1561592655@qq.com, b859744303@qq.com, c308798482@qq.com,d1327723335@qq.com,

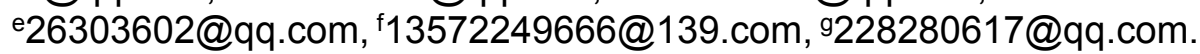

\begin{abstract}
China is in the early stage of the new electricity market reform. The new electric power company will change its electricity sales side to participate in the power market trading through the sales company. The rationality of the trading model of the sales company in the early stage of the new reform will have a great impact on the cost of both the buyer and the seller. This paper proposes a centralized bidding method based on the spread back spread strategy from the point of view of the sales company. By introducing the return coefficient, the bidder returns the bidding spread to both parties in proportion to reduce the transaction costs of both parties. Based on the experience of foreign countries and the actual situation of the new electricity reform in our country, the paper suggests that the power company adopt the centralized bidding method based on the spread back spread strategy and adopt $80 \%$ electricity medium- and long-term bilateral negotiation and $20 \%$ electricity real-time electricity to adopt spread back strategy Focus on bidding transactions and give examples of specific deals.
\end{abstract}

Keywords: New electricity market, spread strategy, Power Company, sales company.

\section{Introduction}

Since the 1980s, countries around the world have broken the power monopolies. The electricity market reform has been carried out by releasing the electricity side, reducing the cost of electricity generation and reducing the electricity price. Now, the electricity market reform has achieved good results [1-3] in the UK, the United States, northern Europe and other western countries. In February 10, 2002, China issued the "power system reform program", and put forward the 16 words electricity reform policy of "separation of plants and networks, separation of main and auxiliary businesses, separation of transmission and distribution, bidding online". The power generation enterprises were separated into five power generation groups to form power generation side competition [4]. However, after years of reform, only the "separation of the plants and networks, separation of the main and auxiliary businesses" was completed, and the pilot in a small range operation results of "separation of transmission and distribution, bidding online" were all failed [5].

There are still many problems in the power industry after the last round of electricity reform. In November 30, 2015, the national development and reform commission (NDRC) issued totally six core documents include the "Implementation opinions on promoting the sale side reform" to support the implementation of the new electricity reform. The general idea of the new electricity reform is to break the monopoly, introduce the competition mechanism, open up the competition of the purchase and sale of electricity, and control the intermediate link [6].

The flowing figure shows the structure of electricity trading in the new electricity reform: 


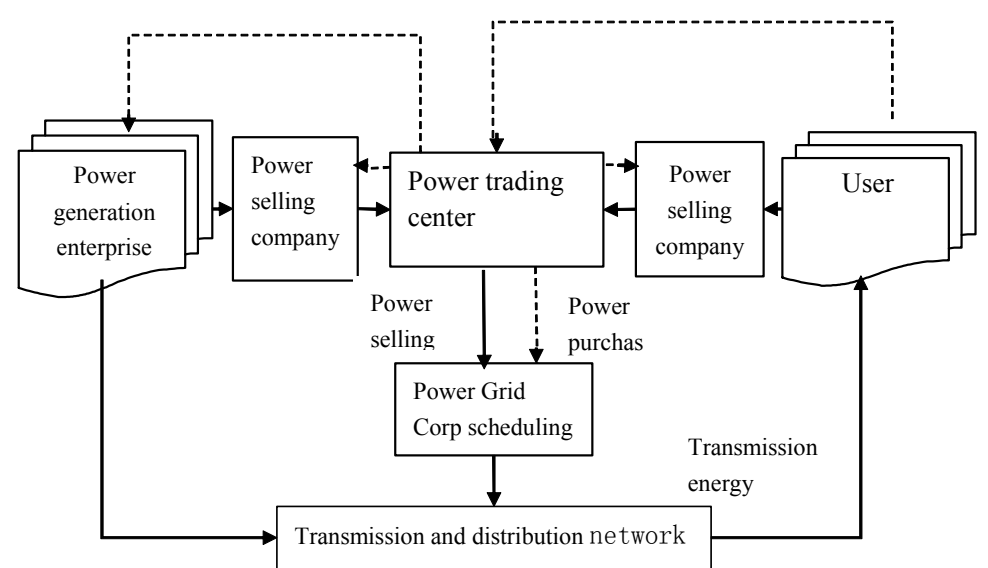

Figure 1 . The structure of electricity trading in the new electricity reform

As can be seen from the figure 1 above, in the process of power market transaction, power selling company and users are involved in the electricity market transaction through the sale of electric company agents. Power generation declare their power capacity and price, users provide their required quantity and price, both sides form a transaction contract through the sale of electricity companies in the power trading center and returns to the power selling company and users, and finally they complete the final transaction through the dispatching and distribution of power grid company. The capital of this transaction structure goes to the power trading center which users pay the fee to. The power trading center is responsible for payment to power plants, power selling companies and power grids separately, and power trading center charged fees to ensure the security of the funds. This new model will form a competition mechanism on the purchase and sale side, eliminate the influence of the unified purchase and sale on the electricity price mechanism, which will help to reduce the user cost and break the original monopoly mechanism.

At present, most of the provinces in China have established electric power trading centers, but most of them have not yet entered the stage of substantive selling electricity and market competition. Therefore, it is of great significance to formulate the specific mode of purchasing and selling electricity in the early stage of the new electricity reform market. This paper summarizes the experience of foreign countries and combines the actual situation of the current new electric power reform in China. It suggests power selling company trade $80 \%$ power with long-term bilateral consultative trading mode, and trade $20 \%$ power with centralized bidding mode based on the spread back strategy.

\section{Bilateral Consultative Trading Mode}

Bilateral consultative trading mode refers to the purchase and sale of electric power (the power generation enterprise, the power selling company, the state grid, the user) reach a bilateral transaction (including the amount of electricity and its price) contract through negotiation in the power trading center, then the power grid is responsible for scheduling and distribution to complete the final contract transactions [7].

In the bilateral consultative trading mode, the power grid will withdraw from the unified purchase and sale of power, take charge of the power dispatching and distribution, and charge the network fee, and will not participate in the pricing of electricity price.

The simple process of bilateral consultative trading mode is as follows: The first stage, bilateral consultation. Purchase and sale of electric power company electricity, both declare electric quantity, price and time through power selling company, both sides aimed at the price, quantity, time and other issues to negotiate trading scheme. The second stage, transaction audit. The electricity trading center is responsible for examining the feasibility of its transaction, whether it meets the requirements of power grid dispatching, whether the price and electricity of the transaction are reasonable or not and so on. If there is a project that does not meet the requirements, the results and contracts are returned 
to the parties, and then resubmitted to the trading center for review. The third stage, sign a contract and carry out the content of the transaction. After the adoption of the audit, the two sides sign the transaction contract, they record it in the trading center and enter it in the trading plan, and then issue the transaction information to the power grid and the power grid is responsible for dispatching, transmission and distribution. Finally, under the supervision of the power trading center the final transaction goal is completed.

\section{The Centralized Bidding Based on Spread Back Strategy}

Users and power plants who participant in the centralized bidding declare the needed electricity quantity and price difference in the electric power trading platform through power selling company. The electric power trading center carries on the market match pair, then the electric power dispatching organization examines the safety and the transaction object, the transaction electricity and the transaction price are finally determined. According to the difference about the bid price, the buyer should sort the price difference from high and the seller should sort the price difference from low to high. The price difference will be formed according to the bid difference between the seller and the buyer, and the price will be sorted according to the price difference. The match will end when the price difference is smaller than the zero [8].

In the centralized bidding business, the price difference between the power plant's applied price and the on-grid price, the price difference between the price declared by the power purchase and the list price, and we use the two price differentials are matched to form the transaction price difference. The concrete calculation is as follows:

Price difference pair=Price differential declared by a power plant-Price difference for the power purchase (1)

When the price difference is positive, it is impossible to deal with it. When the price difference is negative or zero, the transaction principle is traded according to the minimum price difference priority. The price difference needs to be as low as possible for a power plant if it wants to deal with the power plant as far as possible, but for the power buyers, if you want to make a deal as soon as possible, you need to make as much a price as possible. But the lower price of the power plant, the lower profit of the power plant. The higher the price means the higher cost of the user will be.

Due to the fact that the supplier and the buyer cannot match the price exactly when they make a bid, some of them are too large or too small, which is not good for both parties to reduce transaction costs. Therefore, the electricity market needs to introduce the price difference electricity price to return the clearing mechanism. Simply speaking, calculate the total difference when the price difference is formed. Secondly, determine the release factor of the seller and the buyer, that is, the total price difference is returned to the power plant and the purchaser according to the determined proportion, and then the final transaction price is formed:

1. Calculation of power plants and users of all the transaction volume of the declared total cost of the absolute value of $\Delta E_{\text {total }}$, then introduce spread back coefficient $\beta$, the total cost $\Delta E_{\text {total }}$ will be returned to the contracted plant at the stated return factor of $\beta$, and the user will be returned at the stated return factor of $(1-\beta)$. At present, according to the operation of each province's electricity market $\beta$ recommended provisional value of $25 \%$, That is, $25 \%$ of the absolute value $\Delta E_{\text {total }}$ of the transaction price difference between the power plant and the user is returned to the customer who has completed the transaction and $75 \%$ is returned to the power plant.

2. According to the difference between the declared spread of all power plants and the total declared spread of all power plants, $\Delta E_{\text {returnp }}$ will be returned to each power plant respectively. Finally, each power plant will return the cost of its own power divided by its own electricity output plus its declared spread, which is the final price difference of the power plant.

3. User spread back to the principle and power plants are similar, according to each user to declare the spread of all the users spread the total ratio of $\Delta E_{\text {return }}$ will be returned to each user, and finally each user based on their return the cost of the transaction divided by their turnover, plus the declared spread. 


\section{Bid Case Analysis}

Simulated bid centralized bidding: Suppose that the seller has 3 parties to declare the electricity price and electricity through the electricity sales company; 3 buyers through the electricity sales company to declare the electricity price and electricity. The specific data as follows:

\begin{tabular}{|c|c|c|c|c|c|}
\hline \multicolumn{2}{|c|}{ Table 1. Analog quote (Electricity: 104kW, Electricity price: Penny / kWh) } \\
\hline Seller & Declare power & Declared spread & buyer & Declare power & Declared spread \\
\hline A & 500 & -300 & X & 300 & -50 \\
\hline B & 300 & -400 & Y & 600 & -70 \\
\hline C & 400 & -500 & Z & 300 & -100 \\
\hline
\end{tabular}

Trading center spreads according to the formation of spreads to match. Supply and demand trading (power plants, sales agents of the company) Each of the three parties involved in the bidding and reporting power, the final formation of 9 pairs of spreads, and then spread in accordance with the order of transactions from low to high deal matching transactions.

Table 2. Simulated spreads match the deal (Electricity price: Penny / kWh)

\begin{tabular}{|c|c|c|}
\hline Number & Spread on the pairing & Spread \\
\hline 1 & C-X & -450 \\
\hline 2 & C-Y & -430 \\
\hline 3 & C-Z & -400 \\
\hline 4 & B-X & -350 \\
\hline 5 & B-Y & -330 \\
\hline 6 & B-Z & -300 \\
\hline 7 & A-X & -250 \\
\hline 8 & A-Y & -230 \\
\hline 9 & A-Z & -200 \\
\hline
\end{tabular}

Deal one: According to the match results, the first match the lowest spread on the first pair, the seller $\mathrm{C}$ and the buyer A deal, the seller $\mathrm{C}$ declared power $4 * 106 \mathrm{kWh}$, buyer X declare $3 * 106 \mathrm{kWh}$, $\mathrm{C}$ and $\mathrm{X}$ turnover of $3 \times 106 \mathrm{kWh}$, after the deal, the seller $\mathrm{C}$ remaining $106 \mathrm{kWh}$ failed to complete, the buyer A had purchased the electricity he needed, so the fourth spread of B-X failed, and the seventh spread of A-X failed.

Deal two: The seller $\mathrm{C}$ still has $1 * 106 \mathrm{kWh}$ remaining unsold, then it matches the second pairs of spreads to C-Y transaction, Y needs $6^{*} 106 \mathrm{kWh}, \mathrm{C}$ remaining $1 * 106 \mathrm{kWh}$, then $\mathrm{C}$ and $\mathrm{Y}$ make a deal, so $\mathrm{C}$ completes the electricity transaction declared by oneself, then the third spread of $\mathrm{C}-\mathrm{Z}$ is invalid, and y has $5 * 106 \mathrm{kWh}$ remaining.

Deal three: Match the fifth spread of B-Y transaction, B declared power with $3 * 106 \mathrm{kWh}, \mathrm{Y}$ declared power with the remaining $5^{*} 106 \mathrm{kWh}$, so the transaction is $3 * 106 \mathrm{kWh}$, B has completed its declared power transaction, $\mathrm{Y}$ is still surplus $2 * 106 \mathrm{kWh}$ unfinished.

Deal four: At present there are still 8th and 9th pairs of spreads remaining, then break the 8th spreads of A-Y deals, A declares $5 * 106 \mathrm{kWh}, \mathrm{Y}$ left $2 * 106 \mathrm{kWh}$ without dealings, then A-Y deals $2 * 106 \mathrm{kWh}$ of electricity, when A remaining $3 * 106 \mathrm{kWh}$ of electricity dose not clinch a deal.

Deal five: Match the 9th spread of A-Z trades $3 \times 106 \mathrm{kWh}$ of electricity, at this point all the traders' electricity is fully traded.

At this point matching transaction was completed, with a total volume of $12 \times 106 \mathrm{kWh}$, all traded power plants and all traded users declared spread difference is $\Delta E=\sum\left(P_{\text {plantspread }}-P_{\text {userspread }}\right) \times Q_{\text {deal }}=3.83 \times 10^{6}$ yuan, which returned to the power plant $75 \%, 25 \%$ returned to the user, and then according to the transaction bilateral declaration of the spread of electricity to declare the difference between the total declaration of the electricity price to return the proportion of electricity price spreads. 
Table 3. Simulation of centralized bidding transactions (Electricity: 104kW, Electricity price: Penny

\begin{tabular}{|c|c|c|c|c|c|c|c|c|c|c|}
\hline \multicolumn{10}{|c|}{$/ \mathrm{kWh})$} \\
\hline Number & Seller & $\begin{array}{c}\text { Seller's } \\
\text { electricity }\end{array}$ & Sell & $\begin{array}{c}\text { Seller } \\
\text { quotes }\end{array}$ & Buyer & $\begin{array}{c}\text { Buyer's } \\
\text { electricity }\end{array}$ & Buy & $\begin{array}{c}\text { Buyer } \\
\text { quotes }\end{array}$ & Deal & Spread \\
\hline 1 & C & 400 & 300 & -500 & X & 300 & 300 & -50 & 300 & -450 \\
\hline 2 & C & 100 & 100 & -500 & Y & 600 & 100 & -70 & 100 & -430 \\
\hline 3 & B & 300 & 300 & -400 & Y & 500 & 300 & -70 & 300 & -330 \\
\hline 4 & A & 500 & 200 & -300 & Y & 200 & 200 & -70 & 200 & -230 \\
\hline 5 & A & 300 & 300 & -300 & Z & 300 & 300 & -100 & 300 & -200 \\
\hline
\end{tabular}

Table 4. Simulation of the final transaction price of each party (Electricity price: Penny / $\mathrm{kWh}$ )

\begin{tabular}{|c|c|c|c|c|}
\hline Trading party & Quote & Return $(¥)$ & unit price & final price \\
\hline A & -300 & 717750 & 143.55 & -156.45 \\
\hline B & -400 & 957300 & 319.1 & -80.9 \\
\hline C & -500 & 1197000 & 299.25 & -200.75 \\
\hline X & -50 & 217600 & 72.53 & -122.53 \\
\hline Y & -70 & 304700 & 50.78 & -120.47 \\
\hline Z & -100 & 435200 & 145.06 & -245.06 \\
\hline
\end{tabular}

For users, the high price will make the transaction rate is high, but the user's electricity bill will be higher because of its low return price. If the user's quote is low, the user's electricity bill is low, but the transaction will be low, user may not be able to fully buy their desired power. Therefore, the power price return mechanism will increase the competitiveness of the purchase side, exacerbating the game between the user-side price and electricity.

For power plants, although lower quotations will make less profits for power plants, the increase of return prices will increase the income of power plants and meanwhile increase the turnover rate of power plants. Higher power plant quotations will increase plant profits but the corresponding return price will be reduced, while the transaction volume and transaction rates will be reduced. Therefore, the power price return mechanism will also exacerbate the game on the sales side. The main impact of this mechanism lies in: Spread back to the user can be used as a reward to reduce user costs, power plants can use as compensation to improve plant profits. For users, the low-price quotation will lead to an increase in the risk of failure to deal. For power plants, the low-price quotation will increase the transaction rate. Users' declaration of electricity price game will be more intense, power plants will reduce such games.

\section{Conclusion}

At present, China is in the early stage of new electric power reform, which is currently in the exploratory stage for electric power reform. It cannot completely let go of the electric side of purchase and sale, Based on the current situation in China, it is proposed that the sales company adopt the centralized bidding method based on the spread back spread strategy and adopt medium- and longterm bilateral negotiation and trading of $80 \%, 20 \%$ electricity real-time electricity to take the spread back to the strategy of centralized bidding trading program, This can fully optimize the allocation of resources, both buyers and sellers consider the actual situation, to meet the needs of all parties, effectively reducing the high-power unit generating capacity. With the development of the power market reform, the electricity selling companies not only provide purchase and sale of electricity services, but also provide users with diversified electricity sales packages and provide a full range of intelligent management services.

In short, the electricity market reform will reduce the cost of users, make the market more open and transparent, reduce the consumption of non-renewable resources such as coal and the pollution of the environment, this is in line with China's current power generation process, easy to ensure the safe and stable operation of power. In this mode, $80 \%$ of electricity will be subject to bilateral negotiation transactions to maintain stable grid stability, $20 \%$ of electricity to conduct a centralized 
bidding transaction, to gradually adapt to the new market, in the end, the goal of all the electricity to participate in the centralized bidding will be realized.

\section{Acknowledgments}

This work was supported by the National Natural Science Foundation of China under Grant No.51507141 and Shaanxi Provincial Education Office Fund (17JK0547).

\section{References}

[1]. Wang Zhejiang. Seeing China's Electricity Market Reform from the development of Foreign Power Market, [J]. Shanghai Economic Research, 2008 (9): 89-91.

[2]. Chen Yao, Li Chao, Feng Jibe. The Latest Development Trend of Foreign Electricity Market and Its Enlightenment [J]. Low Carbon World, 2016 (24): 109-110.

[3]. Zeng Ming, Liu Chao, Duane Xinhua, etc. The Experience of US and Nordic Electric Power Bilateral Trading Market Model [J]. East China Electric Power, 2013, 41 (1): 5-10.

[4]. Luo Qin. Research on the Purchase and Sale of Electric Companies in Market Environment [D]. Shanghai Tao Tong University, 2014.

[5]. Shi Lu. Interpretation of a New Round of Power System Reform Program [J]. Science and Technology Innovation Guide, 2016, 13(34):225-226.

[6]. Wang Taizhong. The Feasibility of China's Implementation of Bilateral Electricity Trade Model [J]. Economic System Reform, 2015 (2): 194-200.

[7]. Zhang Sensing, Chen Haiyang, Qu Shao Qing, etc. Analysis on the Efficiency of Bilateral Transaction and Energy Conservation and Emission Reduction in Power Market [J]. East China Power, 2010, 38 (3): 332- 336.

[8]. Qu Guangzhou. Power Market Trading Model [J]. Journal of Industrial Economics, 2003 (1): 91108. 